Supporting information for

\title{
Facet-dependent oxidative goethite growth as a function of aqueous solution conditions
}

\author{
Jennifer H. Strehlau, ${ }^{\dagger}$ Melissa S. Stemig, ${ }^{+}$R. Lee Penn, ${ }^{\dagger *}$ and William A. Arnold ${ }^{\S^{*}}$ \\ ${ }^{\dagger}$ Department of Chemistry, University of Minnesota, 207 Pleasant Street SE, Minneapolis, \\ Minnesota, 55455-0431, United States \\ Department of Psychology, University of Minnesota, 75 E River Road, Minneapolis, Minnesota \\ 55455-0366, United States \\ $\S$ Department of Civil, Environmental, and Geo- Engineering, University of Minnesota, 500 \\ Pillsbury Drive SE, Minneapolis, Minnesota, 55455-0116, United States \\ *Address correspondence to either author: \\ R. Lee Penn: phone: (612) 626-4680, fax: (612)626-7541, e-mail: rleepenn@umn.edu \\ William A. Arnold: phone (612) 625-8582, fax: (612)626-7750, email: arno1032@umn.edu
}

\section{Summary}

7 pages, 7 figures, 1 table

Section S1. Additional experimental methods .............................................................. S2

Figure S1. Flowchart of sequential-spike batch reactors ................................................... S3

Figure S2. Fe(II) adsorption for Gth/Fe(II) concentration samples ..................................... S4

Figure S3. XRD of goethite particles after 18 days with Fe(II) ......................................... S5

Figure S4. Low-temperature magnetic characterization ............................................... S5

Figure S5. Length and width measurements from triplicate trials ...................................... S6

Table S1. User-based uncertainties of particle measurements ........................................... S6

Figure S6. Length and width measurements for dried and never dried TEM preparation ......... S7

Figure S7. Length and width measurements for particles after 18 days with Fe(II)................. S7 
Section S1: Additional experimental methods

SRNOM was purchased from the International Humic Substance Society (IHSS). Acetonitrile (HPLC grade), $\mathrm{FeCl}_{2} \cdot 4 \mathrm{H}_{2} \mathrm{O}$, methanol (HPLC grade), and $\mathrm{NaOH}$ were purchased from Fisher, $\mathrm{NaHCO}_{3}$ from Sigma Aldrich, ferrozine from Alfa Aesar, 4-ClNB from Acros, $\mathrm{NH}_{4} \mathrm{CH}_{3} \mathrm{COO}$ and $\mathrm{H}_{2} \mathrm{SO}_{4}$ from Mallinckrodt, and $\mathrm{HCl}$ from $\mathrm{BDH}$ Aristar. All aqueous experiments were performed in carbonate buffer $(10 \mathrm{mM}, \mathrm{pH} 7.0)$, anaerobically prepared by adding $\mathrm{NaHCO}_{3}$ to deoxygenated ultrapure $\left(18.2 \mathrm{M} \Omega \cdot \mathrm{cm}\right.$, Milli-Q) water and adjusting $\mathrm{pH}$ with $1 \mathrm{M} \mathrm{H}_{2} \mathrm{SO}_{4}$. The stock $\mathrm{Fe}$ (II) solution was prepared by adding $\sim 0.23 \mathrm{~g} \mathrm{FeCl}_{2} \cdot 4 \mathrm{H}_{2} \mathrm{O}$ to $0.2 \mathrm{~mL}$ of $1 \mathrm{M} \mathrm{HCl}$ and the appropriate amount of ultrapure water so that the final concentration was $175 \mathrm{mM}$. This stock solution was remade every seven days. For Fe(II) concentration analyses, a $5 \mathrm{mg} / \mathrm{mL}$ ferrozine stock in ultrapure water was prepared.

An Agilent 1100 Series system and ultraviolet detector was used to quantify 4-CINB concentration. Each sample ( $20 \mu \mathrm{L})$ was injected into the system, equipped with a Zorbax SBC18 column $(4.6 \times 150 \mathrm{~mm}, 5 \mu \mathrm{m})$ and set to measure absorbance at $254 \mathrm{~nm}$. The mobile phase $(0.7 \mathrm{~mL} / \mathrm{min})$ was $70: 30$ acetonitrile $: 1 \mathrm{~g} / \mathrm{L}$ ammonium acetate at $\mathrm{pH}$ 7. 4-Chloronitrobenzene degradation was analyzed by first order kinetics $\left(\ln \left([4-\mathrm{ClNB}]_{t} /[4-\mathrm{ClNB}]_{0}\right)\right.$ vs. $\left.t\right)$. The pseudo-first order rate constant $\left(k_{o b s}\right)$ assumes steady state concentrations of $\mathrm{Fe}(\mathrm{II})$ and the number of available surface sites. 

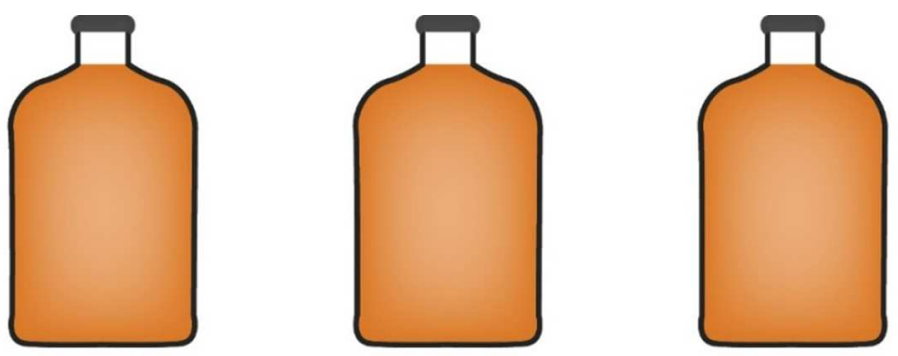

In between spikes:

Replenish Fe(II)

Return to initial $\mathrm{pH}$

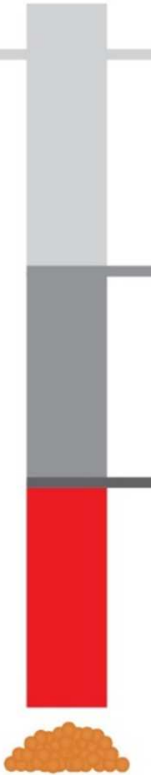

SPIKE 1

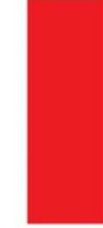

लीक्ष
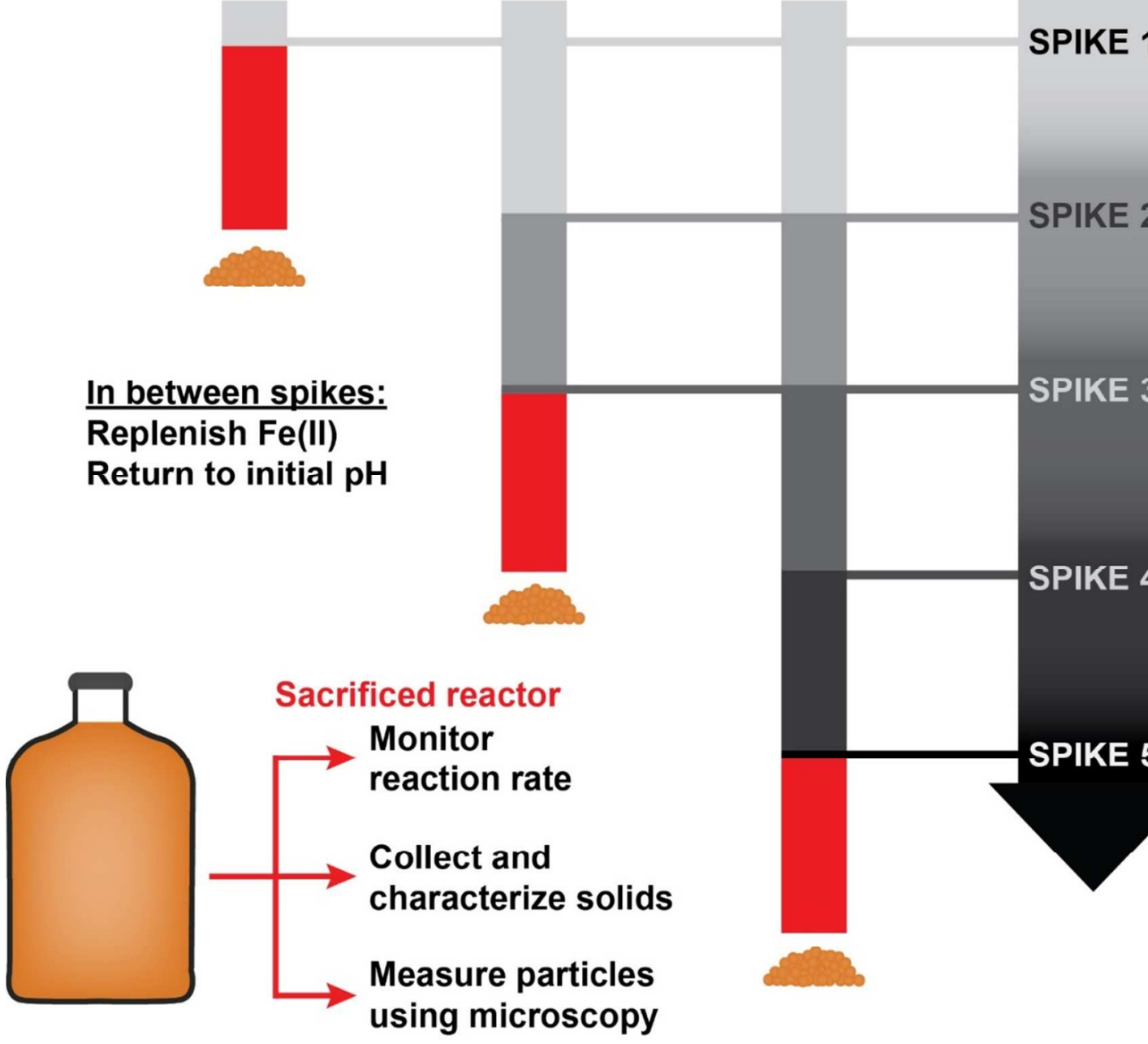

SPIKE 5

SPIKE 3

SPIKE 4

SPIKE 2

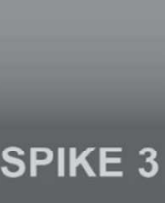

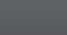

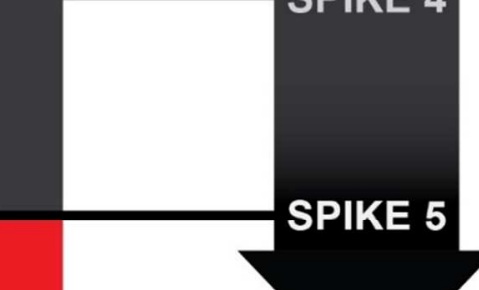

Figure S1: Flowchart for the sequential-spike batch reactors. Adjustments to initial conditions included 1) quantifying [ $\left.\mathrm{Fe}(\mathrm{II})_{\mathrm{aq}}\right]$ with ferrozine analysis, 2) adjusting $\mathrm{pH}$ to 7 (or 6.5) with 0.5 $\mathrm{M} \mathrm{NaOH}, 3$ ) adding $\mathrm{Fe}(\mathrm{II})$ stock solution so that $\left[\mathrm{Fe}(\mathrm{II})_{\mathrm{aq}}\right]=1$ (or $0.5 \mathrm{mM}$ ), and 4) equilibrating $21-24 \mathrm{~h}$ before initiating the next 4-CINB spike. 

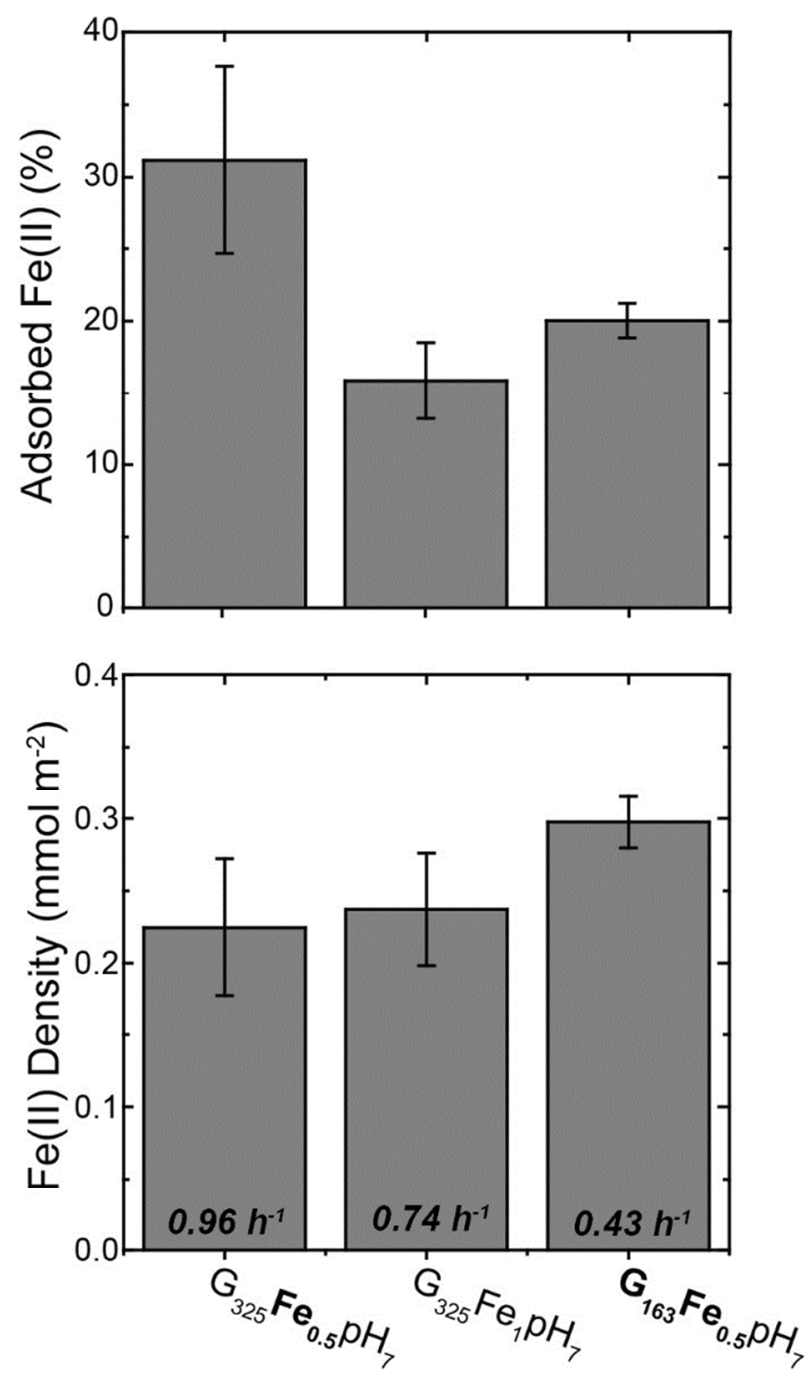

Figure S2: Percent adsorbed Fe(II) and Fe(II) density on goethite after 21 hours of equilibration for samples with adjusted goethite mass loading and Fe(II) concentration. Initial conditions: $\mathrm{G}_{325} \mathrm{Fe}_{1} \mathrm{pH}_{7}=0.325 \mathrm{~g} / \mathrm{L}$ goethite, $1 \mathrm{mM} \mathrm{Fe}(\mathrm{II}) ; \mathbf{G}_{\mathbf{1 6 3}} \mathbf{F e}_{\mathbf{0 . 5}} \mathrm{pH}_{7}=0.163 \mathrm{~g} / \mathrm{L}$ goethite, $0.5 \mathrm{mM}$ $\mathrm{Fe}(\mathrm{II}) ; \mathrm{G}_{325} \mathbf{F e}_{\mathbf{0 . 5}} \mathrm{pH}_{7}=0.325 \mathrm{~g} / \mathrm{L}$ goethite, $0.5 \mathrm{mM}$ Fe(II). Reported are the averages and standard deviations of triplicate trials. Numerical values in bold italics are the $k_{o b s}$ values for each reaction condition. 


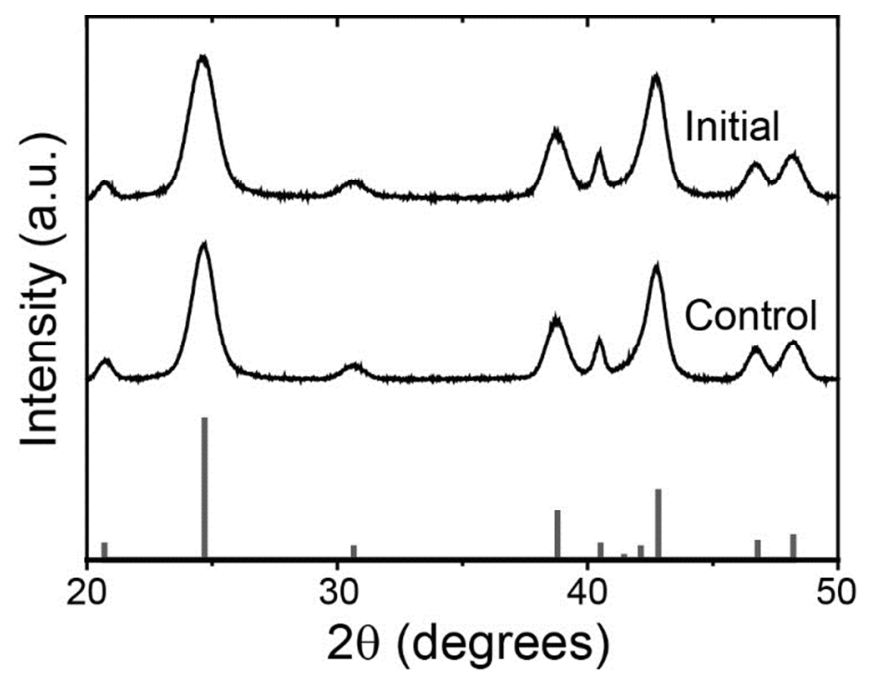

Figure S3. XRD patterns of the initial goethite nanoparticles and goethite after 18 days of stirring in buffer with $1 \mathrm{mM} \mathrm{Fe(II)} \mathrm{(control).} \mathrm{Powder} \mathrm{diffraction} \mathrm{file} \mathrm{for} \mathrm{goethite}=\# 029-0713$, straight lines.

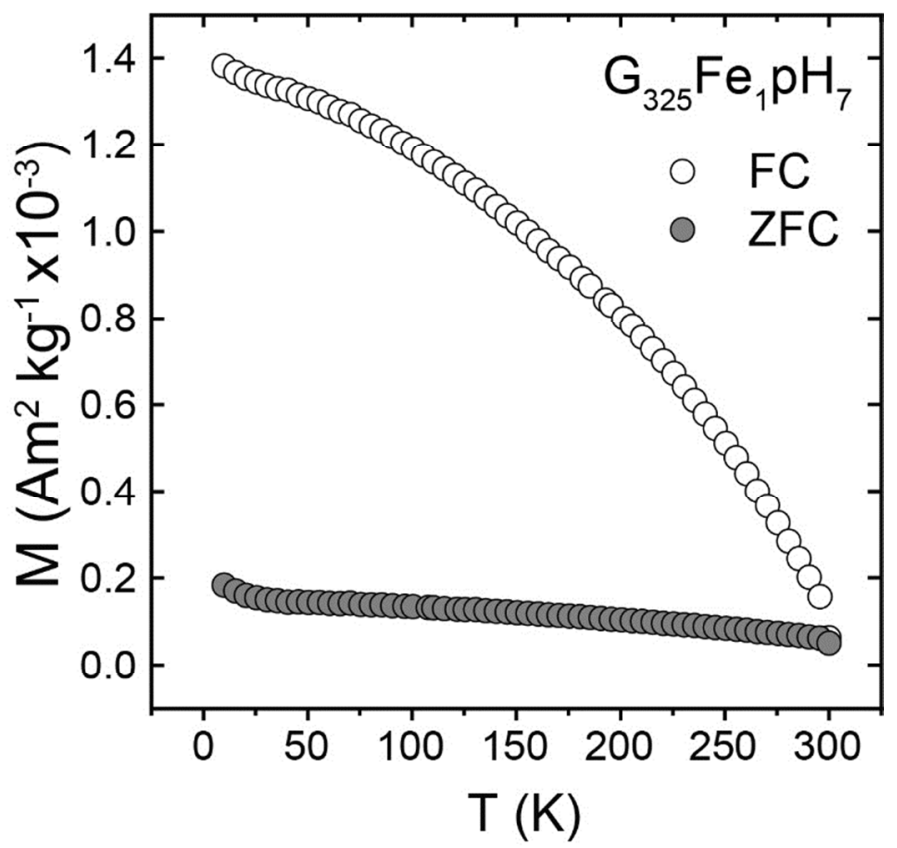

Figure S4. Low-temperature magnetic characterization of sample $\mathrm{G}_{325} \mathrm{Fe}_{1} \mathrm{pH}_{7}$ following five spikes of 4-CINB measuring magnetization $(\mathrm{M})$ as a function of temperature. Field cooling $=\mathrm{FC}$, open circles. Zero-field cooling $=$ ZFC, filled circles. The observed separation of the FC and ZFC curves is characteristic of goethite, with no presence of transitions indicative of other trace iron oxide minerals (e.g., Verwey transition at $120 \mathrm{~K}$ for magnetite). 

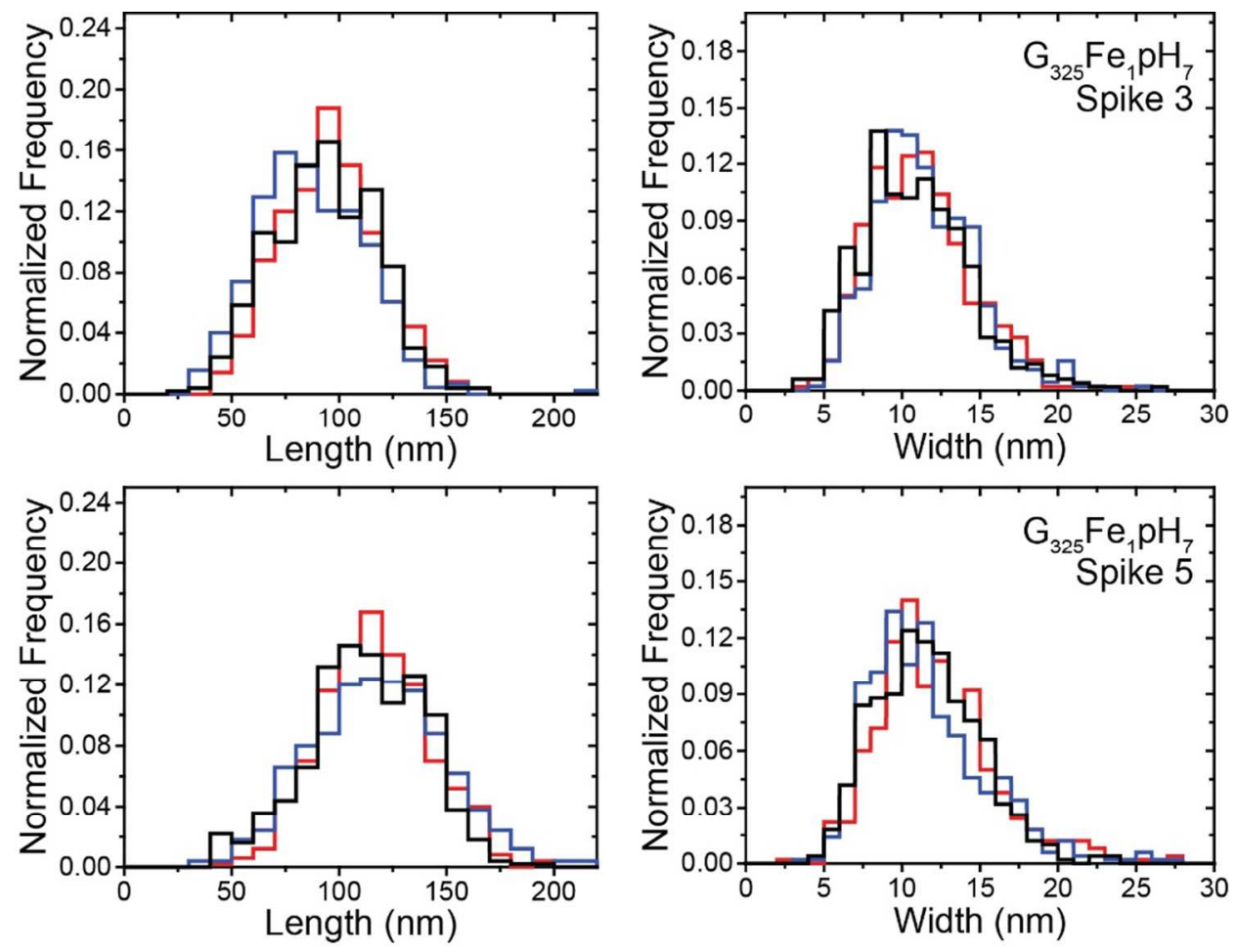

Figure S5. Measurements from triplicate trials for $\mathrm{G}_{325} \mathrm{Fe}_{1} \mathrm{pH}_{7}$ after three (top row) or five (bottom row) spikes of 4-CINB.

Table S1. Uncertainties of particle measurements taken 20 times on separate days.

\begin{tabular}{ccc}
\hline & $\begin{array}{c}\text { Length } \\
\text { Uncertainty }\end{array}$ & $\begin{array}{c}\text { Width } \\
\text { Uncertainty }\end{array}$ \\
\hline Mean (pixels) & $\mathbf{1 . 3}$ & $\mathbf{1 . 1}$ \\
Mean (nm) & $\mathbf{0 . 8}$ & $\mathbf{0 . 7}$ \\
Max (nm) & 1.2 & 0.9 \\
Min (nm) & 0.4 & 0.5 \\
\hline
\end{tabular}



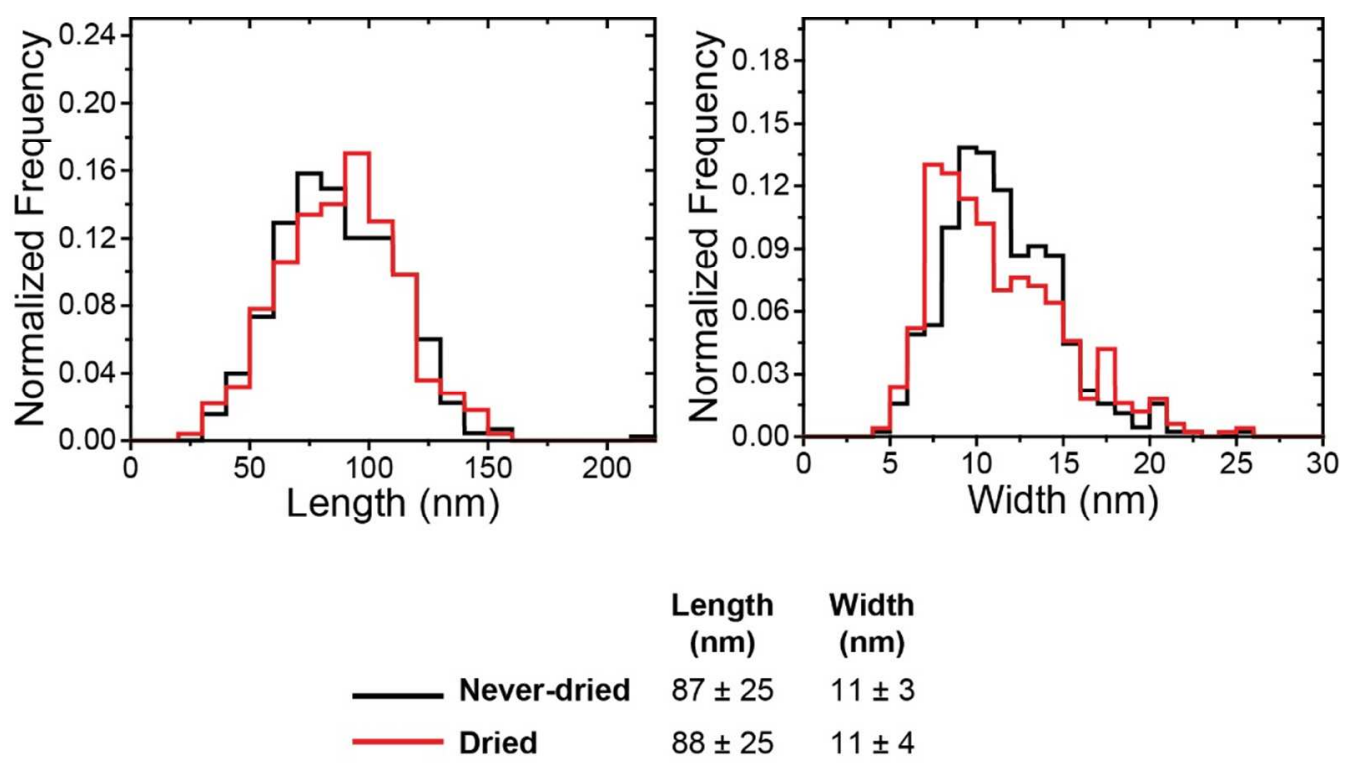

Figure S6. Histograms of length and width measurements of the same sample $\left(\mathrm{G}_{325} \mathrm{Fe}_{1} \mathrm{pH}_{7}\right)$ prepped for TEM by either sampling directly from the reactor and diluting (never-dried, black line) or resuspending dried particles and sonicating (dried, red line).
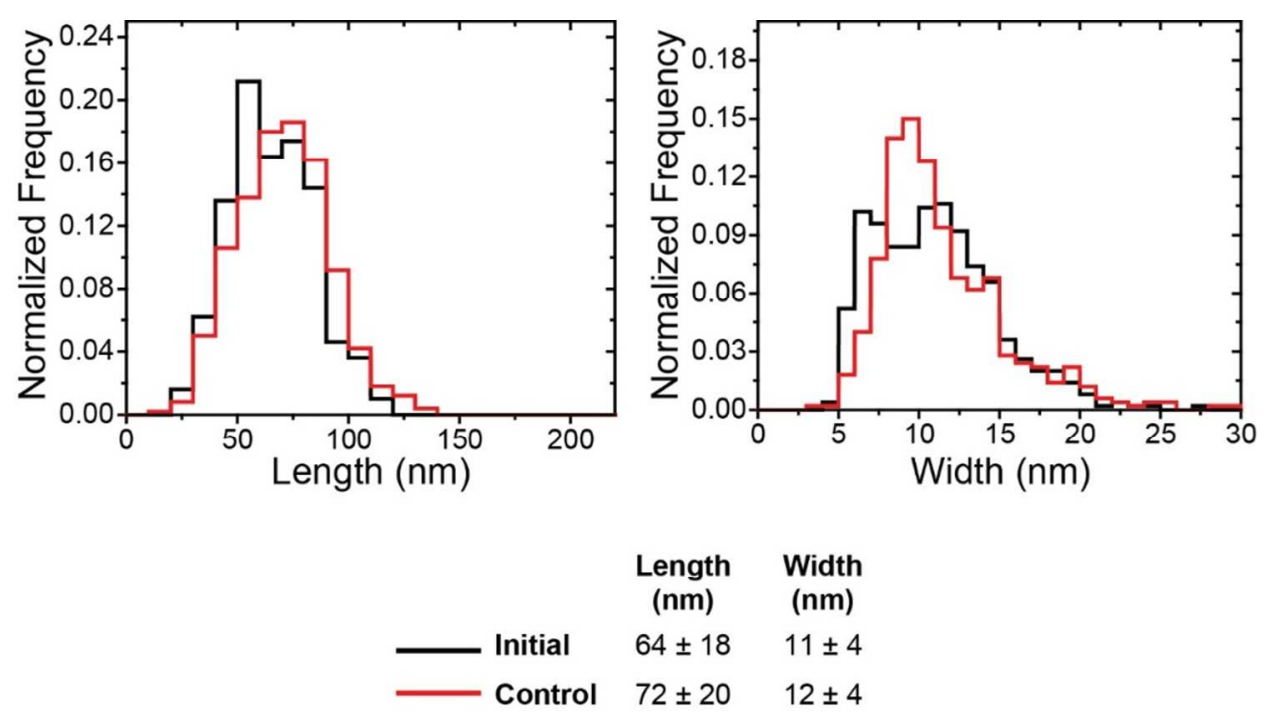

Figure S7. Histograms of length and width measurements of the initial nanoparticles (black line) and goethite after 18 days of stirring in buffer with $1 \mathrm{mM} \mathrm{Fe}(\mathrm{II})$ (control, red line). 